\title{
異なる感觉モダリティ間の遺移における期待効果 表面性状の触感における視觉予測の影霖
}

\author{
柳澤 秀吉 ${ }^{* 1}$, 高辻 賢司 ${ }^{* 2}$

\section{Expectation effect of transitions between different sensory modalities Effect of visual prediction on touch of surface texture}

\author{
Hideyoshi YANAGISAWA $^{* 1}$ and Kenji TAKATSUJ ${ }^{* 2}$ \\ ${ }^{* 1}$ The University of Tokyo. Dept. of Mechanical Engineering \\ 7-3-1, Hongo, Bunkyo-ku, Tokyo, Japan
}

\begin{abstract}
A surface texture is an important factor that affects a product Kansei quality. People perceive a quality of surface texture using different sensory modalities, e.g. vision and touch, and switches them through an interaction with a product, e.g., we see and then touch a product surface. Between such sensory modality transitions, we often expect subsequent modal perceptions using a prior modality, e.g. predicting tactile quality of a product from its appearance before touching. The authors assume that the prior expectation using a modality affects the posterior experience using another modality. In this paper, we propose an evaluation method that identifies the visual expectation effects on tactual experiences. In the method, we synthesize combinations of visual and tactile samples using a half-mirror. Evaluators compare the synthesized samples with a set of real samples used as a tactile scale and select real samples that corresponds to the synthesized samples. We demonstrate the appropriateness of the method with analysis results of roughness using plastic texture samples having different textures, which are commonly used in a product design.
\end{abstract}

Key Words : Product surface texture, disconfirmation of expectation, tactile sensation, visual expectation effect, roughness perception.

\section{1. 粕 $\overline{\mathbf{D}}$}

質感や使用の心地よさなどの感性に評価を依存する製品の品質（以下，感性品質とよぶ）は，製品の魅力に寄 与する設計要件である(1). 製品表面の質感は，様々な製品において共通する感性品質である. 表面の質感を構成 する属性として, 材質, 表面の性状, 色彩, 光沢などが挙げられる.一方, 表面に対してヒトが知覚する質感は, 光沢感やすべり感などの単一の感覚における特徵（以下, 質感特徵（texture feature）とよぶ）と, 触り心地の良 さなどの総合的な質感（以下，総合的質感（complex texture）とよぶ）がある.

ヒトが知覚する質感特徵は感覚モダリティによって異なる．たとえば，視覚で，表面の色彩 (明度, 彩度, 色 相など)，光沢などの質感特徵を知覚し，触覚で，硬さ，冷たさなどの質感特徵を知覚する. また，粗さなどの表 面の性状は，視覚と触覚の両方で知覚可能な質感特徵である．製品表面の質感を設計するためには，製品が使用 される状況において想定される感覚モダリティの条件のもと，設計属性とヒトが知覚する質感との関倸を明らか にした上で，目的とする質感を奏現する設計属性を計画する必要がある．そのために，ヒトがある感覚モダリテ イの条件において表面の質感をどの様に知覚するかを評価し, 評価に対応する表面の属性および特徵を抽出する 方法が望まれる.これまでに, 単一の感覚モダリティの条件下における表面の質感に対する感性の評価法と特徴 抽出に関する方法は数多く検討されてきた(2)(3). また, 異なる感覚モダリティ間における感性の差異を検討した研 究もある(4).

\footnotetext{
${ }^{* 1}$ 正員, 東京大学 大学院工学系研究科（广113-8656 東京都文京区本郷 7-3-1）

"2 非会員, 東京大学 大学院工学系研究科

E-mail: hide@mech.t.u-tokyo.ac.jp
}

[No.12-17] 日本機械学会 第 22 回設計エ学・システム部門講演会講演論文集[2012.9.26-28,広島] 
ところが，実際の製品の使用場面では，単一の感覚モダリティだけでなく異なる感覚モダリティを時系列で遷 移させて対象全体の質感を捉える場合が少なくない，たとえば，製品を見てから触る場合，視覚から触覚へ感覚 モダリティを遷移させている，感覚モダリティの時系列的な遷移においては，遷移前の感覚モダリティ（たとえ ば視覚）で遷移後の感覚モダリティ（たとえば触覚）の知覚内容を予測することがある. 遷移前の感覚モダリテ イによる予測は遷移後の知覚内容にも影響しうる．たとえば，大きさの異なる同一の重さの物体は，大きい物体 の方が持ち上げた際に軽く知覚されることが知られている(5).これは, 物体の大きさを視覚上の手がかりとして 予測した重さの影響であると考えられる．しかし，表面の質感においては，事前の視覚による予測が，事後の触 感の知覚へ与える影響を明らかにした研究は見当たらない.

これまでに，筆者らは，ハーフミラーを用いて視覚用サンプルと触覚用サンプルを仮想合成する実験装置を用 いて, 視覚による事前の予測が触感に与える影響（以下, 視覚による期待効果とよぶ）を確認している ${ }^{(6)}$. 工業 製品に用いられるプラスチックのサンプルプレートを用いた実験の結果から, 同一の触覚用サンプルであっても, 合成する視覚用サンプルによって触感が変化することを確認した．しかし，その効果がどの程度であるかの定量 的な評価には至っていない.

そこで, 本研究では, 視覚と触覚にもとづく感覚モダリティの遷移において, 視覚による予測が触覚の知覚に 与える影響を定量的に評価可能とする手法を提案する. 具体的には, 以下の二点を明らかとする評価手法である.

（1）視覚の期待効果を視覚無しの触覚評価尺度上にマッピングする.これにより，視覚の期待効果の度合い を定量的に評価可能とする.

（2）期待効果の要因となるテクスチャの物理属性 (テクスチヤ表面の粗さや硬さ等)の条件を明らかにする.

提案手法を, 工業製品で用いられる標準的なプラスチック・シボサンプルに適用し, 視覚の期待効果とその条 件を明らかにする，具体例として表面性状の粗さ感を対象とし，視覚による事前の予測が触覚による粗さ評価に 及ぼす影響について報告する。

\section{2. 来材表面の䝿惑および期待効果}

Karana らは, 製品表面の素材の選択において重要となる選定基準について, 20 名の工業デザイナにインタビュ 一を実施した結果から，1) 五感を通して知覚される感覚的な特性，2）知覚される価值, 連想, 感情, 文化的意 味などの無形の特徵（ICM: Intangible characteristics of materials, 以下, ICM とよぶ)，3）加工方法, 而久性, など の技術的特性，および 4) 環境適合性や成形性などの設計要件の 4 点を抽出している(7).このうち，1)および 2) に関する情報の要求は高いにも関わらず，3)および4)に比べて入手しにくい現状を指摘している．また，ICMに 奇与する重要な因子として，五感を通して知覚される感覚的な特性を挙げている.

素材やテクスチャに対する感覚的な特性の情報を提供するための方法として，知覚の評価次元を抽出する検討 がなされている. たとえば，Hollins らはコーデュロイや紙すりなど日常的に触ることのある 17 種の素材表面 を被験者に触らせ, それらの知覚上の非類似度を回答させた ${ }^{(4)}$. 回答結果を多次元尺度構成法により分析した結 果，粗い/滑らか（rough/smooth）および柔らかい/硬い（softhard）の直交する二軸を共通する次元として抽出 した. さらに，粘つく/滑る (sticky/slippery）を，第三の評価軸の可能性として抽出している.（ただし，実験に 使用したサンプル間の識別に対する寄与率は粗い/滑らか，および柔らかい/硬いよりも小さい.)

素材表面の質感は，視覚や触覚に代表される感覚モダリティによって知覚される.また，視覚または触覚のよ うに単一の感覚だけでなく，複数の感覚の組合せとして質感が知覚される場合もある. 複合的な感覚による質感 の知覚においては，各感覚の寄与の度合いが異なる．また，各感覚の寄与度は，評価する対象の複雑さに影響を 受けることが指摘されている ${ }^{(8)}$. Lederman らは，複数のドット（微細な突起）を有するテクスチャ表面の空間密 度と粗さを視覚と触覚で知覚する場合，それぞれの奇与度を重みとした線形和で表すことができるとしている.

そして, 各感覚の奇与度は, 粗さや空間密度など評価する特徵によって変更されるとしている( ${ }^{(9)}$.

一方, ユーザーと製品との関わりにおいては，単数または複数の感覚モダリティを時系列で切り替えて，対象 を知覚する場合が一般的である．たとえば，店舗で製品を手に取る状況では，まず視覚で確認してから実際に手 にとって触覚によりその質感を知覚する．この様な感覚モダリティの遷移においては，遷移前の感覚モダリティ で遷移後の感覚モダリティにおける知覚を予測する場合がある．遷移前の感覚モダリティによる予測は遷移後の 
知覚内容自体にも影響しうることが経験的に知られている.この影響は，事前の期待が事後の経験に影響する期 待効果と考えることができる. 代表的な期待効果のパターンとして，同化と対比が知られている. 同化とは事前 の期待に事後の経験が同化される現象を指寸。一方，対比は事前の期待と事後の経験との差が実際以上に大きく （対比して）知覚される現象である. たとえば，食品科学の分野においては，食品の見た目が味に影響すること が知られており，視覚と味覚の間における期待効果に関寸る研究が行われている ${ }^{(10)}$. また，マーケティング分野 における期待一致理論（Expectation confirmation theory）では，製品に対する期待と実際の不一致が満足度に影響 するとされている(11)．つまり，製品に対する満足は，製品がユーザーに提供する効用だけでなく，製品の経験前 の期待に影響を受けるとしている.

一方で, テクスチャの質感においてその影響を研究した例は少ない. 著者の一人である Yanagisawa らは, 物体を持ち上げた際の重さ知覚において,物体表面のテクスチャの視覚的特徵が影響することを被験者実験 により示している(3).この実験では, 被験者に異なるテクスチャの表面を有する同一形状かつ重量の物体を 手で持ち上げさせ, その重さを回答させている. その結果, 同一の重量かつ形状であるにも関わらず, 持ち 上げ時の把持力と重さの知覚が物体により異なった.この要因として, 表面のテクスチャから予測される摩 擦係数や, 色彩および光沢から連想される材質の重さと実際の重さを手がかりとした期待効果を挙げている.

しかし，テクスチャの質感自体に対する視覚の期待効果について検討した研究は，1章で述べた筆者らの 研究 ${ }^{(6)}$ 以外に見当たらない. テクスチャの視覚的特徵が, 触覚による質感知覚に影響するのであれば, テク スチャが適用される製品の使用状況によって異なる感覚モダリティとその遷移に応じて, 視覚の期待効果を 考慮したテクスチャの選定および設計が必要になる. 逆に, 視覚の期待効果が予測できれば, その影響を利 用して視覚特徴と触覚特徵の組み合わせにより，従来にない触感をもたらすテクスチャの創成が可能になる.

\section{3. 提㚓する評俩 · 分析手法}

提案手法は，見てから触る触感と触るだけの触感を直接的に比較し，それらの触感の差異を視覚の期待効果と して直接抽出する方法にもとづく．以下に具体的な方法を述べる.

図 1 に示す様に，評価サンプルを一対ずつ左右に提示する．その際，一方は見てから触る条件（左側），他方は 比較用触覚サンプルとして触覚のみの条件（右側）で提示する．評価者は，左右のサンプルを触察し触感の違い を設定する評価尺度で比較評価する. 例えば,「右が粗い,「同じ粗さ」、「左が粗い」という項目から回答を得る. そして, 左右のサンプルの触感が同程度となった比較用触覚サンプルを, 見てから触る条件での触感とする．こ のとき，同程度とした比較用触覚サンプルと見てから触るサンプルが，設定した触感の評価尺度（たとえば，粗 さ）においてどの程度異なるかを調べることで, 視覚による期待効果の度合いを評価する. 視覚による期待効果 を系統的に調べるために，見てから触る感覚条件の評価は，視覚用サンプルと触覚用サンプルを別に用意し，八 一フミラーを用いて仮想合成する.このハーフミラーを用いた評価手法の有効性は既報にて検証済みである(6). 視覚用サンプルと触覚用サンプルの全組み合わせについて評価を実施することにより, 視覚の期待効果に寄与す る表面の物理属性を抽出する.

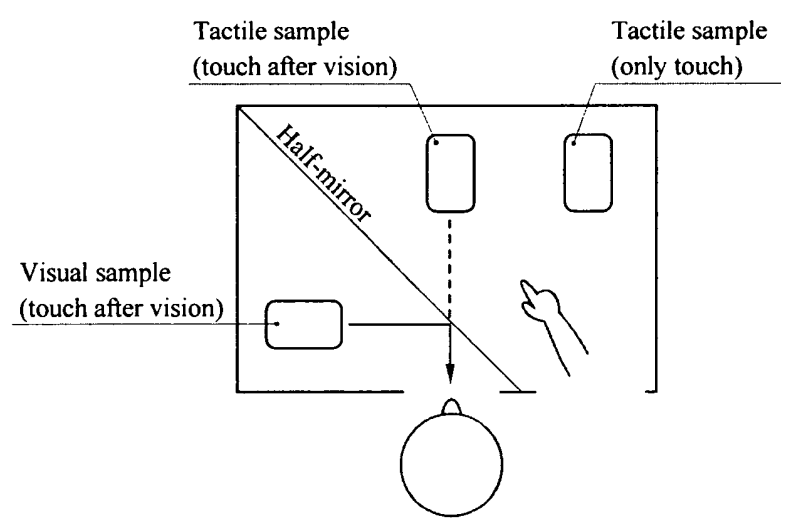

Fig.1 Evaluation apparatus 


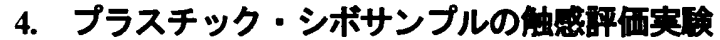

提案した評価手法の有効性を検証するため，プラスチック・シボサンプルを用いた被験者による評価実験を実 施した. プラスチックのシボは, 工業製品に広く用いられるテクスチャである. 5 名の 20 代学生を被験者として, 4 種類の評価サンプル（JIDA STANDARD SAMPLES より選定）を，提案手法に基づき評価させた．評価サンプ ルの属性を表 1 に示す. 粗さの数值は梨地深さの平均差を表す．これら 4 種類の評価サンプルは視・触の仮想合

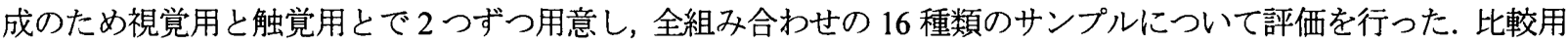
の触覚サンプルは HIPS 樹脂とし，梨地 16.53 から梨地 74.60 までの梨地 10 種と平滑面の計 11 種類を用意した. これらの梨地サンプルは，金型加工で可能な範囲で最小である細かい表面から，一般的に使用される梨地として 最大のものまで, 10 段階で設定されたものである. 評価項目はテクスチャを構成する最も主要な評価因子(4)であ る「粗さ」とし,「右が粗い」,「同じ粗さ」、「左が粗い」の 3 水準で評価させた. 評価サンプルの触り方は右手人 差し指で横方向になぞることとした．また，実験時間の観点から，比較用の触覚サンプルは予め粗さ順に並べて 一度に提示した. 比較手順は, 順序効果を考慮して, 平滑面から梨地 74.60 まで上昇系列で比較評価させた後, 梨地 74.60 から平滑面まで下降系列で比較評価させた.

Table 1. Characteristic of evaluation samples

\begin{tabular}{|c|c|c|}
\hline No. & Material & Texture type and roughness $[\mu \mathrm{m}]$ \\
\hline 1 & HIPS resin & Flat \\
\hline 2 & HIPS resin & Pear-skin 46.14 \\
\hline 3 & ABS resin gloss plated & Flat \\
\hline 4 & ABS resin gloss plated & Pear-skin 46.14 \\
\hline
\end{tabular}

Table 2. Characteristic of scale of roughness

\begin{tabular}{|c|c|c|}
\hline No. & Material & Texture type and roughness $[\mu \mathrm{m}]$ \\
\hline 1 & HIPS resin & Flat \\
\hline 2 & HIPS resin & Pear-skin 16.53 \\
\hline 3 & HIPS resin & Pear-skin 24.07 \\
\hline 4 & HIPS resin & Pear-skin 29.84 \\
\hline 5 & HIPS resin & Pear-skin 33.95 \\
\hline 6 & HIPS resin & Pear-skin 42.59 \\
\hline 7 & HIPS resin & Pear-skin 46.14 \\
\hline 8 & HIPS resin & Pear-skin 56.54 \\
\hline 9 & HIPS resin & Pear-skin 59.62 \\
\hline 10 & HIPS resin & Pear-skin 64.61 \\
\hline 11 & HIPS resin & Pear-skin 74.60 \\
\hline
\end{tabular}

\section{5. 期待効果の抽出結果と考寮}

視覚による期待効果を抽出するため，比較評価で「同じ粗さ」とされた比較用の触覚サンプルを調べる．図 2 から図 5 に, 仮想合成用の各触覚サンプルに対して得られる視覚の期待効果を示す. 図の横軸は比較用の触覚サ ンプル，縦軸は「同じ粗さ」と評価した回数の合計を示す．図中の縦の実線は触覚サンプルの実際の粗さを示す. 同じ粗さとする比較サンプルが，実際の粗さよりも粗い加工の場合，視覚情報が無い場合よりも視覚の予測があ る場合のほうが触覚サンプルをより粗く知覚されていることを意味する.

図 2 は仮想合成用の触覚サンプルが HIPS 樹脂の梨地 46.14 であった場合の, 視覚サンプル毎の期待効果を示し ている. 視覚サンプルが HIPS 樹脂の梨地 46.14 で仮想合成用の触覚サンプルと同じだった場合, 同じ粗さと評価 する回数が最も多いのは，より粗い面を持つ梨地 56.54 であった，すなわち，視覚による予測がある場合の HIPS 
樹脂の梨地 46.14 触覚サンプルは, 触覚のみの場合よりもやや粗く知覚される傾向があることがわかる. 視覚サ ンプルを HIPS 樹脂の平滑面にした場合も同様の傾向がみられる. 視覚サンプルを ABS 樹脂メッキの平滑面にし た場合，梨地 64.61 および梨地 74.60 で「同じ粗さ」とした回答数がもっとも高く，実際の粗さより粗いサンプル であった． 視覚サンプルを ABS 樹脂の梨地 46.14 にした場合，同じ粗さと評価する回数が最も多い比較用触覚サ ンプルは梨地 59.62 で，実際の粗さより粗いサンプルであった．以上の結果から，仮想合成用の触覚サンプルが HIPS 樹脂の梨地 46.14 である場合, 視覚サンプルの材質が ABS 樹脂メッキだった場合, 視覚サンプルが触覚サ ンプルと同じである触覚評価に比べてより粗く知覚される傾向が確認された. 特に, 視覚サンプルが ABS 樹脂メ ッキの平滑面である場合には, HIPS 樹脂の梨地 46.14 の触覚評侕が受ける「より粗く」感じる効果は顕著であり， その大きさは梨地 64.61 または梨地 74.60 の粗さ加工と同程度に知覚されるほどであるとわかる.この要因として, 事前の期待と事後の経験との差が実際以上に大きく知覚される対比効果が考えられる. すなわち, 事前に視覚で 滑らかな面を予測し，実際の触覚がその予測よりも粗いと，視覚の予測が無い触覚だけの触感よりも，より粗く 知覚される現象であると考えられる.

図 3 は仮想合成用の触覚サンプルが ABS 樹脂メッキの梨地 46.14 である場合の視覚サンプルごとの期待効果を 示している. いずれの視覚サンプルにおいても粗さが同程度とした回数の最も多いのは梨地 42.59 であり, 視覚 情報による変化は小さい. よって, ABS 樹脂メッキの梨地 46.14 という属性は視覚の期待効果を受けにくいこと がわかる.

図 4 は仮想合成用の触覚サンプルが HIPS 樹脂の平滑面である場合の視覚サンプルごとの期待効果を示してい る.いずれの視覚サンプルにおいても粗さが同程度とした回数の最も多いのは平滑面であり，視覚情報による変 化は小さい.

図 5 は仮想合成用の触覚サンプルが ABS 樹脂メッキの平滑面である場合の視覚サンプルごとの期待効果を示し ている. いずれの視覚サンプルにおいても粗さが同程度とした回数の最も多いのは平滑面であり，視覚情報によ る変化は小さい. よって, 平滑面は視覚の期待効果を受けにくいことがわかる. このような視覚の期待効果に対 する而性は，対象とするテクスチャや材質において視覚の期待効果を考慮すべきか否かを判断する指標となると 考えられる.

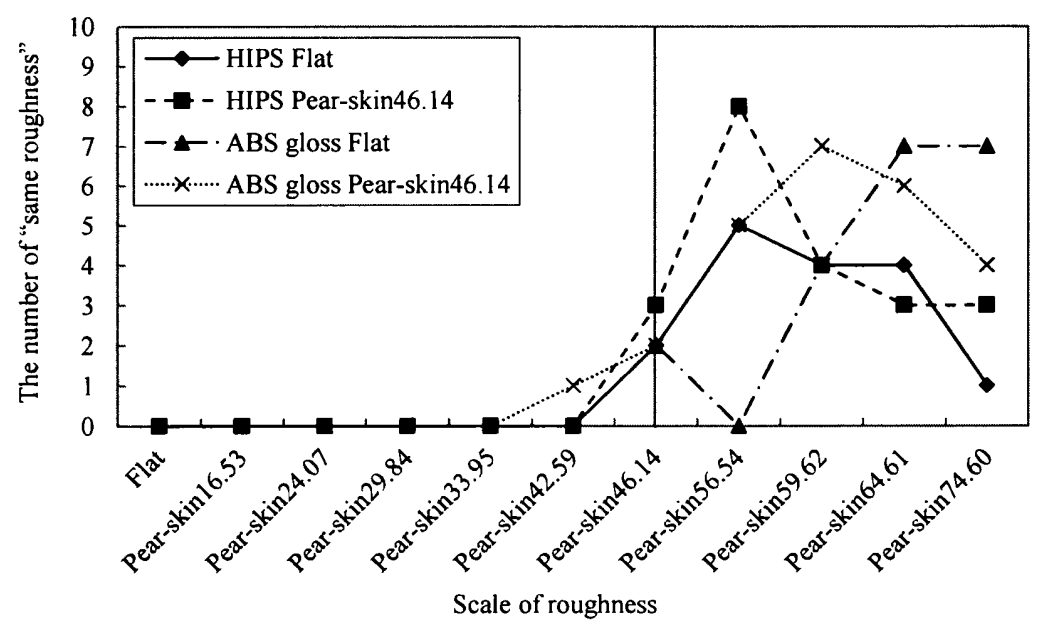

Fig.2 Visual expectation effect on HIPS pear-skin 46.14 as tactile samples 


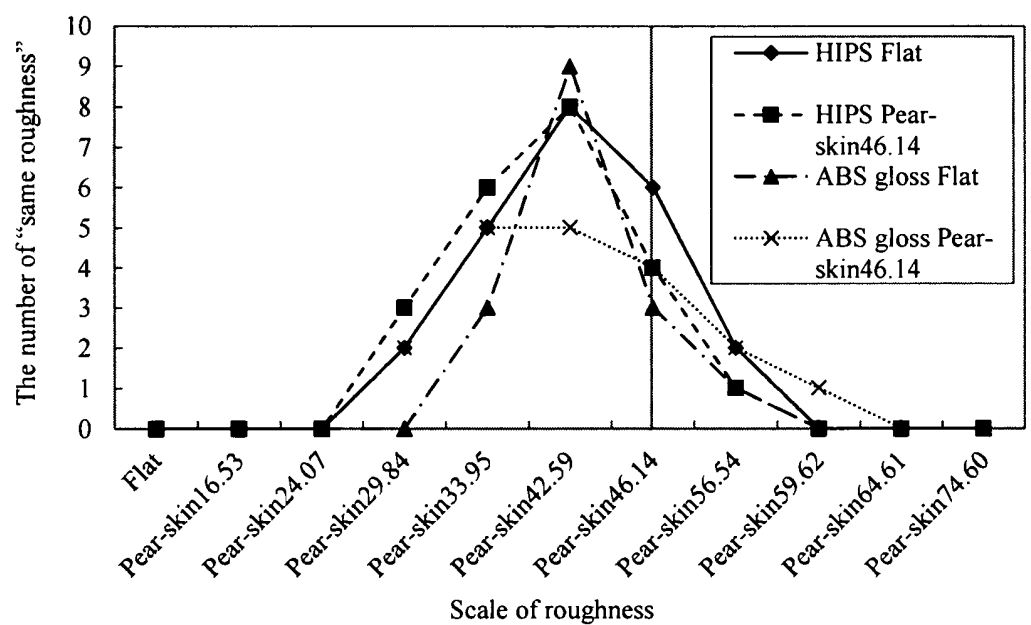

Fig.3 Visual expectation effect on ABS gloss pear-skin 46.14 as tactile sample

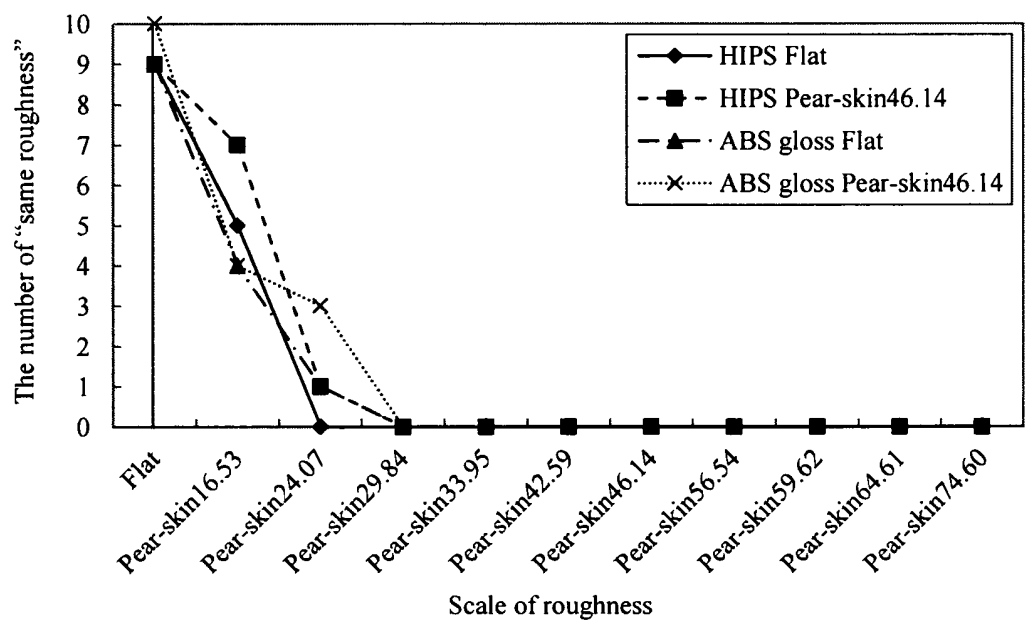

Fig.4 Visual expectation effect on HIPS Flat as tactile samples

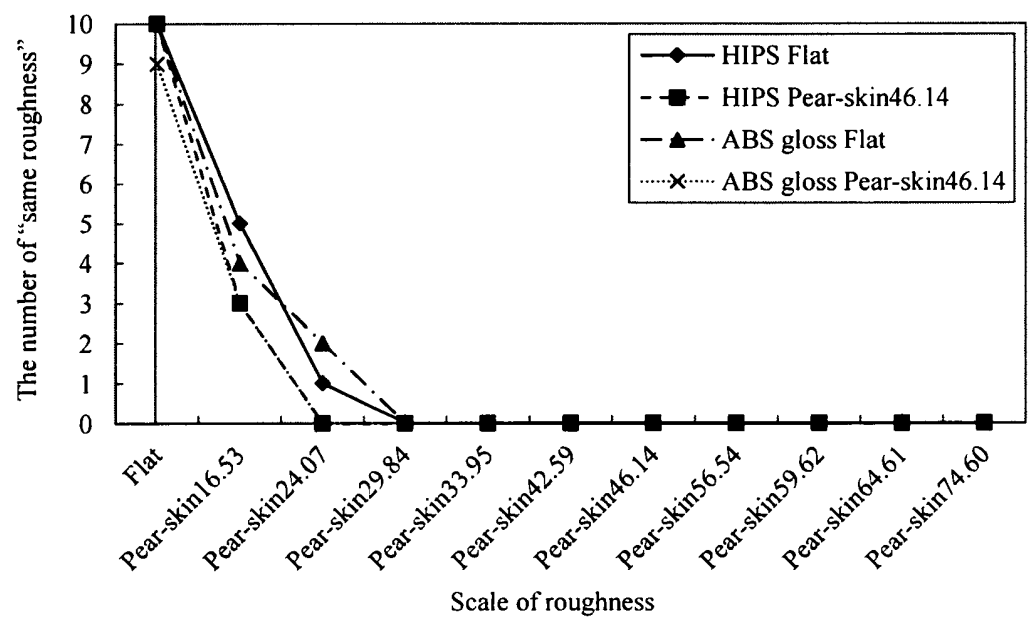

Fig.5 Visual expectation effect on ABS gloss Flat as tactile sample 


\section{6. 結 语}

視覚の期待効果を考慮した触感評価手法として，視覚の期待効果を抽出し，その度合いを把握する評価・分析 手法を提案した．本手法は見てから触る条件と触覚のみの条件を同時に提示した際の両者の比較評価から，期待 効果を直接評価可能とした． 提案手法をプラスチック・シボサンプルに適用した結果の一例として，視覚サンプ ルが ABS 樹脂メッキの平滑面である場合, HIPS 樹脂の梨地 46.14 が受ける期待効果は「より粗く感じる」効果 であることを確認した，そして，その粗さ感は梨地 64.61 を視覚情報なしで触察した場合と同程度であることを 示した. この要因として事前の期待と事後の経験との差が実際以上に知覚される対比効果が考えられる. また平 滑面といら属性は視覚用サンプルを変えても触覚評価が変動しないことを確認し，視覚の期待効果に対する而性 が触覚用サンプルによって異なることを示した．提案手法を用いることで視覚の期待効果の度合いとその発生条 件に関する情報をデザイナに提供し，テクスチャを選定あるいは新たにデザインする際の指針として利用するこ とが期待される.

\section{文献}

(1) Yanagisawa H., \& Fukuda S., "Interactive Reduct Evolutionary Computation for Aesthetic Design", Transactions of the ASME, Journal of Computing and Information Science in Engineering, Vol. 5, No. 1 (2005), pp. 1-7.

(2) Motoyoshi I., Nishida S., Sharan L., \& Adelson E.H., "Image statistics and the perception of surface qualities", Nature, Vol. 447, No. 7141 (2007), pp. 206-209.

(3) Yanagisawa H., \& Yuki N., "Sensory Modal Transition from Expectation to Experience: A Case of Lifting Objects Having Different Surface Texture", KEER2012, (2012).

(4) Hollins M., Bensma a, S., Karlof K., \& Young F., "Individual differences in perceptual space for tactile textures: Evidence from multidimensional scaling", Perception \& Psychophysics, Vol. 62, No. 8 (2000), pp. 1534-1544.

(5) Flanagan J.R., \& Beltzner M.A., "Independence of perceptual and sensorimotor predictions in the Size-weight illusion", Nature Neuroscience, Vol. 3, No. 7 (2000), pp. 737-741.

(6) Yanagisawa H., \& Takatsuji K., "A method for evaluating tactile sensation with visual expectation effect", KEER2012, (2012).

(7) Karana E., Hekkert P., \& Kandachar P., "Material considerations in product design: A survey on crucial material aspects used by product designers", Materials \& Design, Vol. 29, No. 6 (2008), pp. 1081-1089.

(8) Klatzky R.L., Lederman S.J., \& Matula D.E., "Haptic exploration in the presence of vision", Journal of Experimental Psychology: Human Perception and performance, Vol. 19, No. 4 (1993), pp. 726-743.

(9) Lederman S.J., Thorne G., \& Jones B., "Perception o texture by vision and touch: Multidimensionality and intersensory integration", Journal of Experimental Psychology: Human Perception and Performance, Vol. 12, No. 2 (1986), pp. 169-180.

(10) Cardello A.V., \& Sawyer F.M., "Effects of disconfirmed consumer expectations on food acceptability", Journal of sensory studies, Vol. 7 (1992), pp. 253-277.

(11) Oliver R.L., "A cognitive model of the antecedents and consequences of satisfaction decisions", Journal of Marketing Research, Vol. 17, No. 4 (1980), pp. 460-469. 